\title{
Distinct muscarinic acetylcholine receptor subtypes mediate pre- and postsynaptic effects in rat neocortex
}

Sylvain Gigout ${ }^{1}$, Gareth A Jones ${ }^{2}$, Stephan Wierschke ${ }^{1}$, Ceri H Davies ${ }^{2}$, Jeannette M Watson ${ }^{2}$ and Rudolf A Deisz ${ }^{1 *}$

\begin{abstract}
Background: Cholinergic transmission has been implicated in learning, memory and cognition. However, the cellular effects induced by muscarinic acetylcholine receptors (mAChRs) activation are poorly understood in the neocortex. We investigated the effects of the cholinergic agonist carbachol (CCh) and various agonists and antagonists on neuronal activity in rat neocortical slices using intracellular (sharp microelectrode) and field potential recordings.

Results: CCh increased neuronal firing but reduced synaptic transmission. The increase of neuronal firing was antagonized by pirenzepine ( $M_{1} / M_{4}$ mAChRs antagonist) but not by AF-DX $116\left(M_{2} / M_{4}\right.$ mAChRs antagonist). Pirenzepine reversed the depressant effect of CCh on excitatory postsynaptic potential (EPSP) but had marginal effects when applied before CCh. AF-DX 116 antagonized the depression of EPSP when applied before or during CCh. CCh also decreased the paired-pulse inhibition of field potentials and the inhibitory conductances mediated by $G A B A_{A}$ and $G A B A_{B}$ receptors. The depression of paired-pulse inhibition was antagonized or prevented by AF-DX 116 or atropine but only marginally by pirenzepine. The inhibitory conductances were unaltered by xanomeline $\left(M_{1} / M_{4}\right.$ mAChRs agonist), yet the CCh-induced depression was antagonized by AF-DX 116. Linopirdine, a selective M-current blocker, mimicked the effect of CCh on neuronal firing. However, linopirdine had no effect on the amplitude of EPSP or on the paired-pulse inhibition, indicating that M-current is involved in the increase of neuronal excitability but neither in the depression of EPSP nor paired-pulse inhibition.

Conclusions: These data indicate that the three effects are mediated by different mAChRs, the increase in firing being mediated by $M_{1} m A C h R$, decrease of inhibition by $M_{2} m A C h R$ and depression of excitatory transmission by $\mathrm{M}_{4} \mathrm{mAChR}$. The depression of EPSP and increase of neuronal firing might enhance the signal-to-noise ratio, whereas the concomitant depression of inhibition would facilitate long-term potentiation. Thus, this triade of effects may represent a "neuronal correlate" of attention and learning.
\end{abstract}

Keywords: Carbachol, M-current, Muscarinic acetylcholine receptors, Sensorimotor cortex, Cognition, Synaptic transmission

\section{Background}

Considerable evidence indicates a crucial role of acetylcholine (ACh)-mediated transmission in learning and memory. Impairment of cholinergic signalling contributes to cognitive deficits in animal models [1] and diseases such as schizophrenia and Alzheimer's Disease [2-4]. Conversely, drugs that augment cholinergic transmission (e.g. donepezil

\footnotetext{
* Correspondence: rudolf.deisz@charite.de

${ }^{1}$ Center for Anatomy, Institute for Cell Biology and Neurobiology, Charité

Universitätsmedizin Berlin, Philippstr. 12, 10115 Berlin, Germany

Full list of author information is available at the end of the article
}

or galatamine) have been shown to improve certain cognitive functions $[5,6]$. In this context metabotropic ACh receptors, termed muscarinic ACh receptors (mAChRs) [7] play a crucial role. Five $\mathrm{mAChR}$ subtypes have been cloned $\left(M_{1}-M_{5}\right)$; each consisting of seven highly conserved transmembranal segments. A large and more variable intracellular domain [8] couples the receptor to second messengers and ion channels via heterotrimeric G-proteins $[1,7,9,10]$.

The mAChRs are now recognized as key targets for the treatment of different neuropathologies such as Alzheimer's Disease, schizophrenia and Parkinson's Disease 
[10]. In particular, agonists of $M_{1} m A C h R$ or antagonists at $\mathrm{M}_{2}$ or $\mathrm{M}_{4} \mathrm{mAChRs}$ are promising substances [10,11].

However, the similarity in ligand-binding sites between mAChR subtypes, the paucity of selective agonists/antagonists as well as the expression of different subtypes of $\mathrm{mAChRs}$ in a given area constitute major obstacles to delineate cellular effects of a given subtype [1]. The improvement of therapeutic approaches using specific mAChR modulators is further impeded by a lack of established and validated protocol to screen efficacy of different mAChR agonist/antagonist at native receptors in neocortical slices. Characterization of receptors in a native system is a crucial issue. For instance, at $\mathrm{D}_{2}$-type dopamine receptors [12] or AMPA receptors [13], the pharmacology at recombinant receptors critically depends on the experimental conditions. Thus, the pharmacology of $\mathrm{mAChR}$ in heterologous systems may not necessarily relate to the natively expressed mAChR [14]. Therefore, to delineate the pharmacology of mAChRs in the neocortex, the data must be obtained in the native neocortical slice.

We tried to define simple paradigms to quantify routinely the efficacy of different $\mathrm{mAChR}$ agonists. This should facilitate further screening for novel drugs in the neocortex. We investigated the effects of $\mathrm{CCh}$ and various $\mathrm{mAChR}$ antagonists on several parameters of neuronal excitability and the synaptic transmission in neocortical layer II/III. We have chosen layer II/III of neocortex because of the established expression of $M_{1}, M_{2}$ and $M_{4}$ but not $M_{3}$ and $M_{5}$ mAChRs at the mRNA [15] and the protein levels [15-18].

As a first step we tested whether the published effects obtained under various experimental conditions can be reproduced. Firstly, in neocortical pyramidal neurones, $\mathrm{ACh}$ or the prototype cholinergic agonist carbamylcholine-chloride (carbachol, CCh) depolarizes the membrane potential and increases action potential (AP) firing [19-21]. Secondly, CCh reduces excitatory postsynaptic potentials (EPSPs) in neocortical neurons $[21,22]$. This depressant effect was reduced by the preferential $M_{1} / M_{4}$ and $M_{2} / M_{4}$ mAChRs antagonists (pirenzepine and AFDX 116, respectively) and was not due to activation of nicotinic receptors [22]. Thirdly, ACh reduces the GABA release in neocortex via activation of $\mathrm{M}_{2} \mathrm{mAChR}$ and to a smaller extent by activation of $\mathrm{M}_{1} \mathrm{mAChR}$ [23].

Here we show that these 3 effects are mediated by 3 different subtypes of mAChRs allowing screening for mAChRs subtype-specific agonists/antagonists.

\section{Results}

Modulation of neuronal properties and firing behaviour

In control conditions, neurones had a resting membrane potential $\left(E_{m}\right)$ of $-76.2 \pm 0.4 \mathrm{mV}$, an input resistance of $20.4 \pm 0.8 \mathrm{M} \Omega$ and the AP amplitudes averaged $92.4 \pm 0.7 \mathrm{mV}(\mathrm{n}=92)$. The slope of neuronal AP firing was $57.3 \pm 1.6 \mathrm{APs} / \mathrm{nA}$ in control conditions.
Effects of CCh on membrane properties and neuronal firing

Bath application of $\mathrm{CCh}$ had no effect on $\mathrm{E}_{\mathrm{m}}$ (control: $-75.5 \pm 0.7 \mathrm{mV}$, CCh: $-74.8 \pm 0.7 \mathrm{mV} ; \mathrm{n}=40, p>0.05)$ or AP amplitudes (control: $89.5 \pm 1.2 \mathrm{mV}$, CCh: $88.5 \pm 1.3 \mathrm{mV} ; \mathrm{n}=40, p>0.05)$. However, CCh consistently increased the neuronal input resistance (control: $20.4 \pm 1.3 \mathrm{M} \Omega$, CCh: $24.2 \pm 1.4 \mathrm{M} \Omega ; \mathrm{n}=40, p<0.002)$. During $\mathrm{CCh}$ application a given current injection elicited more APs (Figure 1A, B, C). The slope of neuronal firing averaged $58.4 \pm 2.1 \mathrm{APs} / \mathrm{nA}$ in control and increased to $97.8 \pm 3.4 \mathrm{APs} / \mathrm{nA}$ in the presence of CCh $(n=40, p<0.0001)$, much more than anticipated from the increase in membrane resistance. The reversibility of CCh effect on slope of neuronal APs firing was by $66.4 \pm 6.0 \%$ after washout $(n=10$; Figure $2 \mathrm{~A})$. The subrheobase for AP generation was significantly decreased during perfusion with $\mathrm{CCh}$ (control: $0.5 \pm 0.02 \mathrm{nA}$, CCh: $0.46 \pm 0.02 \mathrm{nA}, \mathrm{n}=40, p<0.01)$.

\section{Pharmacological delineation of the mAChR subtypes involved}

Atropine $(n=7)$ or pirenzepine $(n=7)$ reversed the CChinduced increase of slope of neuronal firing $(p<0.05$ vs CCh alone and $p>0.05 v s$. control; not shown). This antagonism was almost complete and indistinguishable from the reversibility observed after washout $(\mathrm{n}=10 ; p>0.05$; Figure 2A). However, AFDX did not reverse the CChinduced increase of slope of neuronal firing ( $p>0.05 v s$. $\mathrm{CCh}$ and $p<0.05 v s$. control). In fact, the antagonism observed with AFDX $(n=7)$ was much smaller than the reversibility observed after washout $(n=10, p<0.01$; Figure $2 \mathrm{~A}$ ). In the continuous presence of $\mathrm{CCh}$, the antagonism observed during a co-application of "pirenzepine + AFDX" $(\mathrm{n}=8)$ was not different to that obtained during application of pirenzepine alone $(n=7, p>0.05$; Figure 2A). This suggests that the slight antagonism observed during application of AFDX alone is due to some antagonistic effect of AFDX on $M_{1}$ mAChR.

The slope of neuronal firing during application of $\mathrm{CCh}$ in atropine-containing $(n=9)$ or pirenzepine-containing artificial cerebrospinal fluid (ACSF) $(n=7)$ is significantly smaller than that obtained during application of $\mathrm{CCh}$ in standard ACSF ( $n=40, p<0.01$; Figure 2B). However, the slope of neuronal firing during application of $\mathrm{CCh}$ added to an AFDX-containing $\operatorname{ACSF}(n=7)$ is not different to that obtained during application of CCh in standard ACSF ( $n=40, p>0.05$; Figure 2B), i.e. AFDX fails to modify the $\mathrm{CCh}$-induced effects on firing. To further test the involvement of $M_{1}$ mAChR in the effects on firing, we applied xanomeline, a $\mathrm{M}_{1} / \mathrm{M}_{4}$ preferring $\mathrm{mAChRs}$ agonist [24]. Xanomeline increased the slope of neuronal firing from $57.8 \pm 6.5 \mathrm{APs} / \mathrm{nA}$ to $80.4 \pm 7.7 \mathrm{APs} / \mathrm{nA}(\mathrm{n}=11, p<0.001)$.

Together these data suggest that $\mathrm{CCh}$ exerts its action on slope of neuronal firing via $\mathrm{mAChRs}$, and in particular $\mathrm{M}_{1}$ but not $\mathrm{M}_{2}$ or $\mathrm{M}_{4}$ mAChRs. 

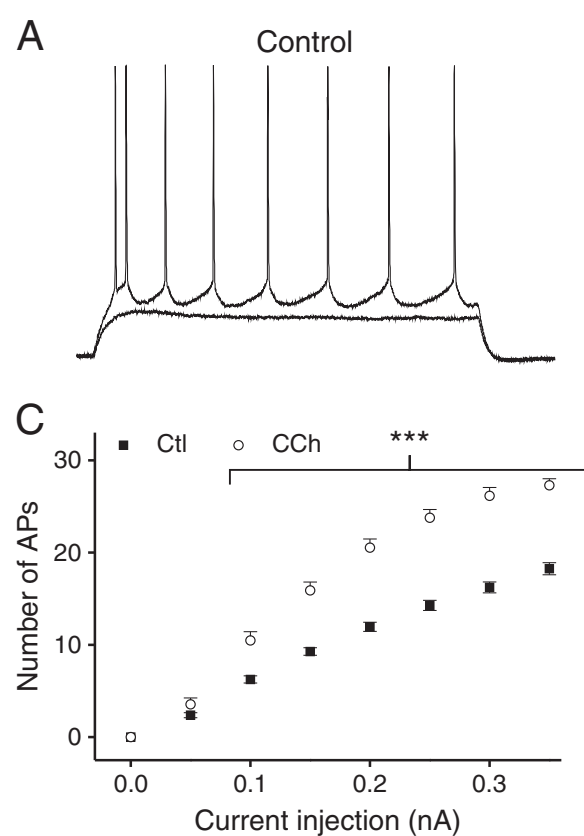

B

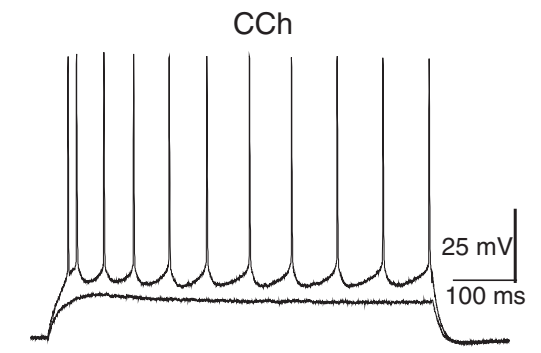

$\mathrm{D}$

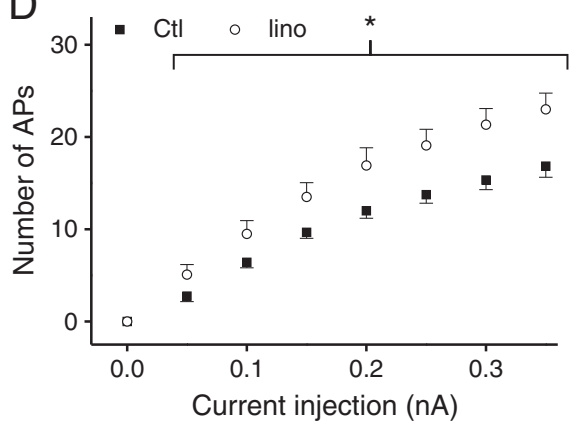

Figure $1 \mathrm{CCh}$ and linopirdine effects on neuronal AP firing. A, B. Voltage traces of a neocortical neurone in control condition (A) and in the presence of $10 \mu \mathrm{M}$ CCh (B). The traces show voltage responses to current injections of 0.40 and $0.50 \mathrm{nA}$ (durations $600 \mathrm{~ms}$ ). Note the increased number of APs in the presence of $10 \mu \mathrm{M}$ CCh compared to control condition. C, D. Plot of the average number of APs vs. current injection in control conditions and in the presence of $10 \mu \mathrm{M} C \mathrm{Ch}(C ; n=40)$ or $10 \mu \mathrm{M}$ linopirdine $(D, n=12)$. These experiments were performed in STRC. *: $p<0.05$ vs. control, ***: $p<0.001$ vs. control.
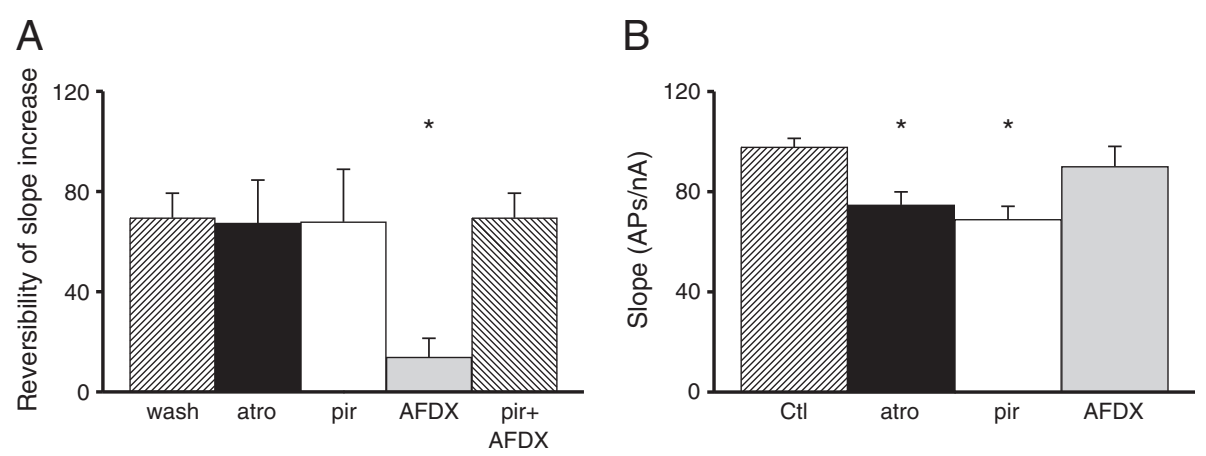

Figure 2 Pharmacology of CCh-induced increase in slope of neuronal APs firing. A. Plot of the reversibility (in \%) of the CCh-induced increase in slope of neuronal APs firing after washout or addition of different mAChR antagonists to a CCh-containing ACSF as indicated. Note the reversibility observed with atropine $(n=7)$ or pirenzepine $(n=7)$ was maximal since not different to that observed after washout $(n=10)$. However, the reversibility observed with AFDX was much smaller to that observed after washout. The reversibility observed during a coapplication of CCh with "AFDX + pirenzepine" $(n=8)$ was not different to that obtained during a co-application of CCh with "pirenzepine alone" $(n=7)$. These experiments were performed in STRC. *: $p<0.05$ vs. reversibility after washout. B. Plot of the slope of neuronal AP firing during CCh addition in standard ACSF or in ACSF containing different mAChR antagonists as indicated. Note the slope of neuronal firing during application of CCh in a atropine-containing ( $n=9)$ or a pirenzepine-containing $(n=7)$ ACSF is significantly smaller to that obtained during application of CCh in standard ACSF $(n=40)$. However, slope of neuronal firing during application of CCh in an AFDX-containing ACSF $(n=7)$ is not different to that obtained during application of CCh in standard ACSF $(n=40)$. These experiments were performed in STRC. The symbols represent: *: $p<0.05$ vs. slope of neuronal firing during application of CCh in standard ACSF. 


\section{CCh-induced increase of neuronal firing is mimicked by M-current blockade}

To test the involvement of $\mathrm{K}_{\mathrm{V}} 7$ channels blockade [9] in the $M_{1}$ mAChR-mediated increase of neuronal firing, we applied linopirdine $(10 \mu \mathrm{M})$, a blocker of $\mathrm{K}_{\mathrm{V}} 7$ channels [25]. Bath application of linopirdine had no effect on AP amplitudes (control: 97.5 $\pm 1.6 \mathrm{mV}$, linopirdine: $95.4 \pm 2.5 \mathrm{mV} ; \mathrm{n}=12, p>0.05)$ or on $\mathrm{E}_{\mathrm{m}}$ (control: $-76.5 \pm 1.1 \mathrm{mV}$, linopirdine: $-75.6 \pm 1.2 \mathrm{mV} ; \mathrm{n}=12, p>0.05$ ) as expected since $\mathrm{K}_{\mathrm{V}} 7$ channels are not activated at $-75 \mathrm{mV}$ [9]. However, linopirdine increased the neuronal input resistance (control: $17.8 \pm 1.8 \mathrm{M} \Omega$, linopirdine: $28.4 \pm 3.2 \mathrm{M} \Omega ; \mathrm{n}=12 ; p<0.0001)$.

Linopirdine increased significantly the number of APs at each current magnitude (Figure 1D). Consequently, the slope was $58.4 \pm 5.1 \mathrm{APs} / \mathrm{nA}$ in control and increased to $79.8 \pm 7.8 \mathrm{APs} / \mathrm{nA}$ in the presence of linopirdine $(\mathrm{n}=12$, $p<0.002)$. The sub-rheobase for AP generation was strongly decreased from $0.58 \pm 0.05 \mathrm{nA}$ in control to $0.36 \pm 0.03 \mathrm{nA}$ in the presence of linopirdine $(\mathrm{n}=12$, $p<0.0001)$.

Bath application of retigabine $(10 \mu \mathrm{M})$, an activator of $\mathrm{K}_{\mathrm{V}} 7$ channels [26], had no effect on AP amplitudes (control: $95.6 \pm 1.6 \mathrm{mV}$, retigabine: $95.1 \pm 2.8 \mathrm{mV} ; \mathrm{n}=7$, $p>0.05$ ), on $\mathrm{E}_{\mathrm{m}}$ (control: $-81.5 \pm 1.6 \mathrm{mV}$, retigabine: $-81.9 \pm 1.6 \mathrm{mV} ; \mathrm{n}=7, p>0.05$ ), or on neuronal input resistance (control: $15.3 \pm 3.3 \mathrm{M} \Omega$, retigabine: $13.3 \pm 1.8 \mathrm{M} \Omega$; $\mathrm{n}=7 ; \quad p>0.05)$. Retigabine decreased significantly the number of APs at each current magnitude (not shown). Consequently, the slope was $53.9 \pm 6.1 \mathrm{APs} / \mathrm{nA}$ in control and decreased to $12.2 \pm 1.9 \mathrm{APs} / \mathrm{nA}$ in the presence of retigabine $(\mathrm{n}=7, p<0.0002)$. The sub-rheobase for AP generation was increased from $0.81 \pm 0.09 \mathrm{nA}$ in control to $0.99 \pm 0.12 \mathrm{nA}$ in the presence of retigabine $(\mathrm{n}=7, p<0.01)$.

\section{Modulation of GABAergic transmission}

\section{CCh decreases the paired-pulse inhibition of field potentials}

Paired-pulse protocols are often used to study GABAergic inhibition in field potentials [27]. We therefore employed a paired-pulse protocol as a first step towards studying CCh modulation of inhibition.

The input-output curves obtained in ITRC $(n=49$; not shown) were qualitatively similar to that obtained in STRC, except for larger amplitudes of potentials ( $p$ $<0.0001$ ), as expected [28]. The amplitude of the field potentials decreased significantly in the presence of $\mathrm{CCh}$ $(10 \mu \mathrm{M})$ at stimulus intensities larger than $0.3 \mathrm{~mA}$ (not shown; $\mathrm{n}=49, p<0.05)$.

This CCh-induced synaptic depression was antagonized by atropine $(n=19)$. Pirenzepine $(n=15)$ and AFDX $(n=16)$ at least partially reversed the CChinduced depression. Linopirdine $(\mathrm{n}=10, p>0.05)$ and retigabine $(\mathrm{n}=8, p>0.05)$ had no effect on synaptic transmission (data not shown).
Paired-pulse stimulations (interpulse intervals: $10 \mathrm{~ms}$ $1 \mathrm{~s})$ were used to determine the magnitude of pairedpulse depression of the second field potentials (FP2). Since the apparent time-to-peak of the intracellular $\mathrm{GABA}_{\mathrm{A}}$-mediated response is about $20-30 \mathrm{~ms}$ [29], we focus here on the results obtained for interpulse intervals of $10-30 \mathrm{~ms}$ to investigate $\mathrm{GABA}_{\mathrm{A}}$ receptor-mediated inhibition. A high stimulus intensity ( $1 \mathrm{~mA})$ was used to maximally activate GABAergic transmission. When two pulses were delivered $20 \mathrm{~ms}$ apart, the mean amplitude of the FP2 was $25 \pm 4 \%$ of the amplitude of the first (FP1; $\mathrm{n}=59)$.

CCh $(10 \mu \mathrm{M})$ decreased slightly the amplitude of FP1 (to $92 \pm 15 \%$ of control value; $\mathrm{n}=49, p<0.05$; Figure $3 \mathrm{~A}$, $\mathrm{B}$ ), whereas the amplitude of FP2 increased strongly (to $342 \pm 50 \%$ of the control value; $\mathrm{n}=49, p<0.0001$ ) for an interpulse interval of $20 \mathrm{~ms}$ (Figure 3A, B). This resulted in an increase of the paired-pulse ratio (PPR) which was significant for interstimulus intervals from $10 \mathrm{~ms}$ to 400 ms (control: $0.24 \pm 0.04$, CCh: $0.69 \pm 0.06$, interstimulus interval $20 \mathrm{~ms} ; \mathrm{n}=49, p<0.0001$; Figure $3 \mathrm{D})$.

\section{$\mathrm{CCh}$ decreases the paired-pulse inhibition via mAChRs}

At interpulse intervals between 10 and $30 \mathrm{~ms}$, both atropine $(\mathrm{n}=19, p<0.05$ vs. $\mathrm{CCh}$ and $p>0.05$ vs. control; Figure 3A, B, C, E) and AFDX ( $\mathrm{n}=15, p<0.05$ vs. CCh and $p>0.05$ vs. control; Figure $3 \mathrm{~F}$ ) antagonized the CCh-induced increase in PPR. In contrast, the CChinduced increase of the PPR at these interstimulus intervals was unaltered by addition of pirenzepine $(\mathrm{n}=14, p>0.05$ vs. CCh and $p<0.05$ vs. control; Figure 3G). Conversely, application of AFDX $(n=6)$ or atropine $(n=5)$ prevented the CCh-induced increase of PPR $(p>0.05 v s$. control; not shown), whereas pirenzepine failed to prevent this CCh-induced increase of PPR ( $\mathrm{n}=7, p<0.05$ vs. control; not shown).

Application of linopirdine had no effect on the PPR ( $\mathrm{n}=10, p>0.68$; Figure $3 \mathrm{H}$ ) suggesting that the M-current blockade is not involved in the CCh-induced increase of PPR. Additionally, we verified that retigabine $(10 \mu \mathrm{M})$ did not alter the PPR (not shown, $\mathrm{n}=8, p>0.05$ ). This suggests that modulation of GABA release, underlying the paired-pulse depression, is dominated by $M_{2}$ mAChR effects. To further rule out the involvement of $\mathrm{M}_{1} / \mathrm{M}_{4} \mathrm{mAChRs}$ in the depression of inhibition, we applied xanomeline. Xanomeline did not alter the PPR $(\mathrm{n}=6, p>0.05)$.

\section{CCh decreases inhibitory synaptic conductances via $M_{2}$ $m A C h R$}

To more directly evaluate the effects of mAChRs on synaptic inhibition, we evaluated the synaptic conductances underlying the $\operatorname{IPSP}_{\mathrm{A}}$ and $\mathrm{IPSP}_{\mathrm{B}}$ in the presence of various $\mathrm{mAChR}$ related compounds. Application of $\mathrm{CCh}$ 


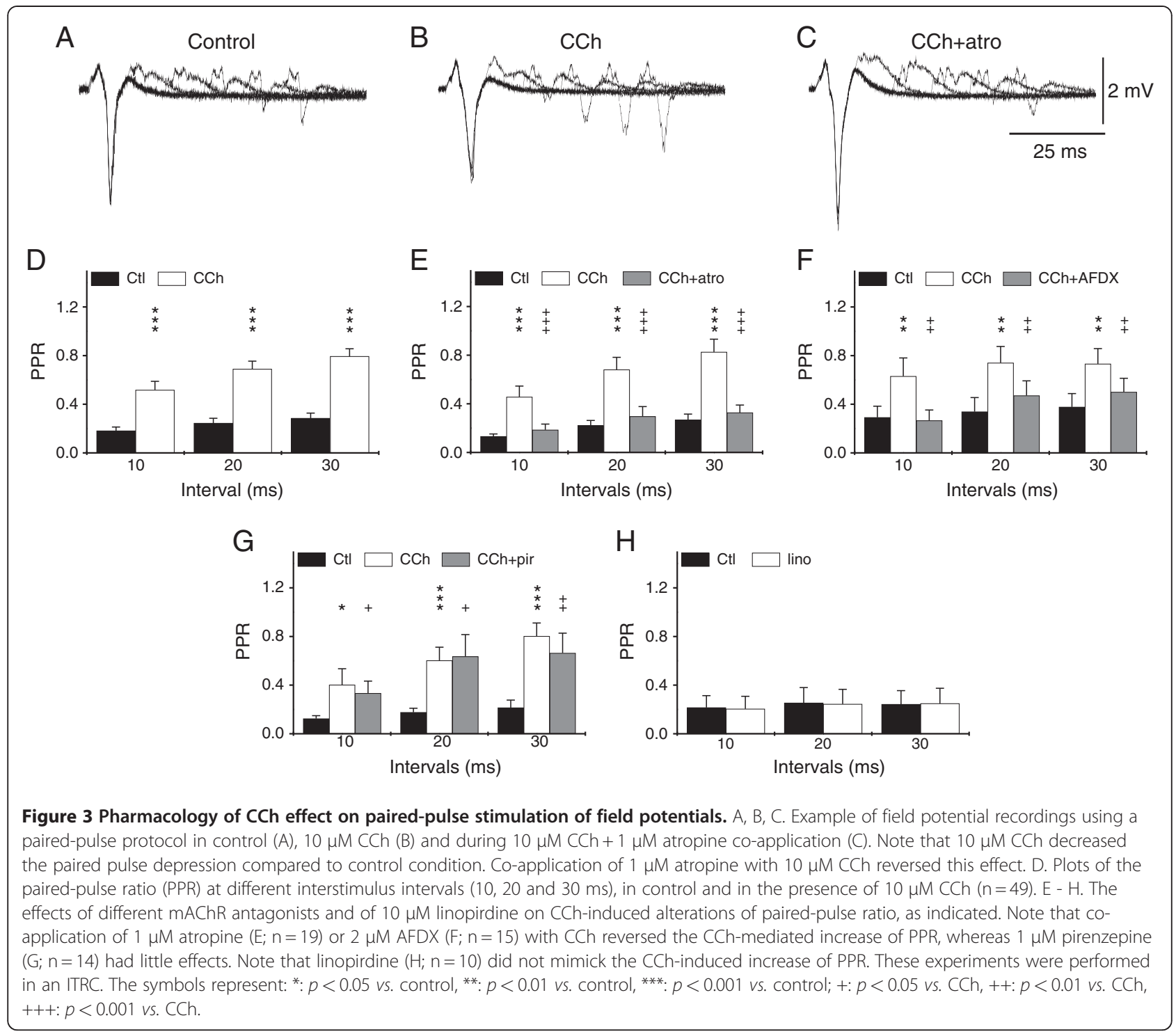

greatly reduced the amplitudes of both, $\mathrm{IPSP}_{\mathrm{A}}$ and $\mathrm{IPSP}_{\mathrm{B}}$ components (Figure $4 \mathrm{~A}, \mathrm{~B}$ ). Estimating the underlying conductances ( $\mathrm{g}_{\text {IPSP }}$ ) revealed substantial decreases; g IIPSP-A $_{\text {A }}$ decreased from $110 \pm 31 \mathrm{nS}$ to $34 \pm 11 \mathrm{nS}$, g decreased from $41 \pm 9 \mathrm{nS}$ to $12 \pm 3 \mathrm{nS}$, i.e. by 69.1 and $69.8 \%$, respectively (Figure $4 \mathrm{E} ; \mathrm{n}=17, p<0.05$ ). To evaluate which subtypes of $\mathrm{mAChRs}$ are involved in this modulation of inhibition we first tested the $M_{2 /} M_{4}$ mAChRs antagonist AFDX in the presence of CCh. In these neurones, $\mathrm{CCh}$ virtually abolished the conductances of both IPSPs ( $g_{\text {IPSP-A }}$ from $32.8 \pm 13.6$ to $0.0 \pm 5.4$ $\mathrm{nS} ; \mathrm{n}=5, p<0.05$ and $\mathrm{g}_{\text {IPSP-B }}$ from $18.7 \pm 4.6 \mathrm{nS}$ to $3.5 \pm 1.4 \mathrm{nS} ; \mathrm{n}=5, p<0.05)$. Application of AFDX caused a considerable reversal in the depression of inhibition recovering to 63 and $72 \%$ of the control values $(p>0.05$ vs. control).
Next we tested the effects of the $M_{1} / M_{4} m A C h R s$ antagonist pirenzepine. Application of $\mathrm{CCh}$ considerably reduced the synaptic conductances, $\mathrm{g}_{\text {IPSP-A }}$ from $104.3 \pm 39.4 \mathrm{nS}$ to $58.9 \pm 29.0 \mathrm{nS}, \mathrm{g}_{\text {IPSP-B }}$ from $25.0 \pm 8.2$ $\mathrm{nS}$ to $13.0 \pm 5.3 \mathrm{nS}$ i.e. on average by 44 and $48 \%$. On addition of pirenzepine, the depression of inhibitory conductances was essentially unaltered (gIPSP-A $: 74.9 \mathrm{nS}$, $p>0.05$ vs. CCh; gIPSP-B: $15.7 \mathrm{nS} p>0.05$ vs. CCh).

To further substantiate our hypothesis of a $\mathrm{M}_{2}$ mAChR-mediated depression of inhibition, we next tested xanomeline to evaluate possible effects of $\mathrm{M}_{1}$ or $\mathrm{M}_{4}$ mAChRs. Application of xanomeline $(3 \mu \mathrm{M})$ had no consistent effect on $E_{m}$ or $R_{m}$ (control $-75.2 \pm 2.0 \mathrm{mV}$, $26.7 \pm 9.0 \mathrm{M} \Omega$ xanomeline: $-76.4 \pm 1.7 \mathrm{mV}, 26.1 \pm 9.7 \mathrm{M} \Omega$ $p>0.05)$. These neurones exhibited the usual alteration of slope of firing (increasing from $64.4 \pm 10.7$ to $79.4 \pm 10.9$ 

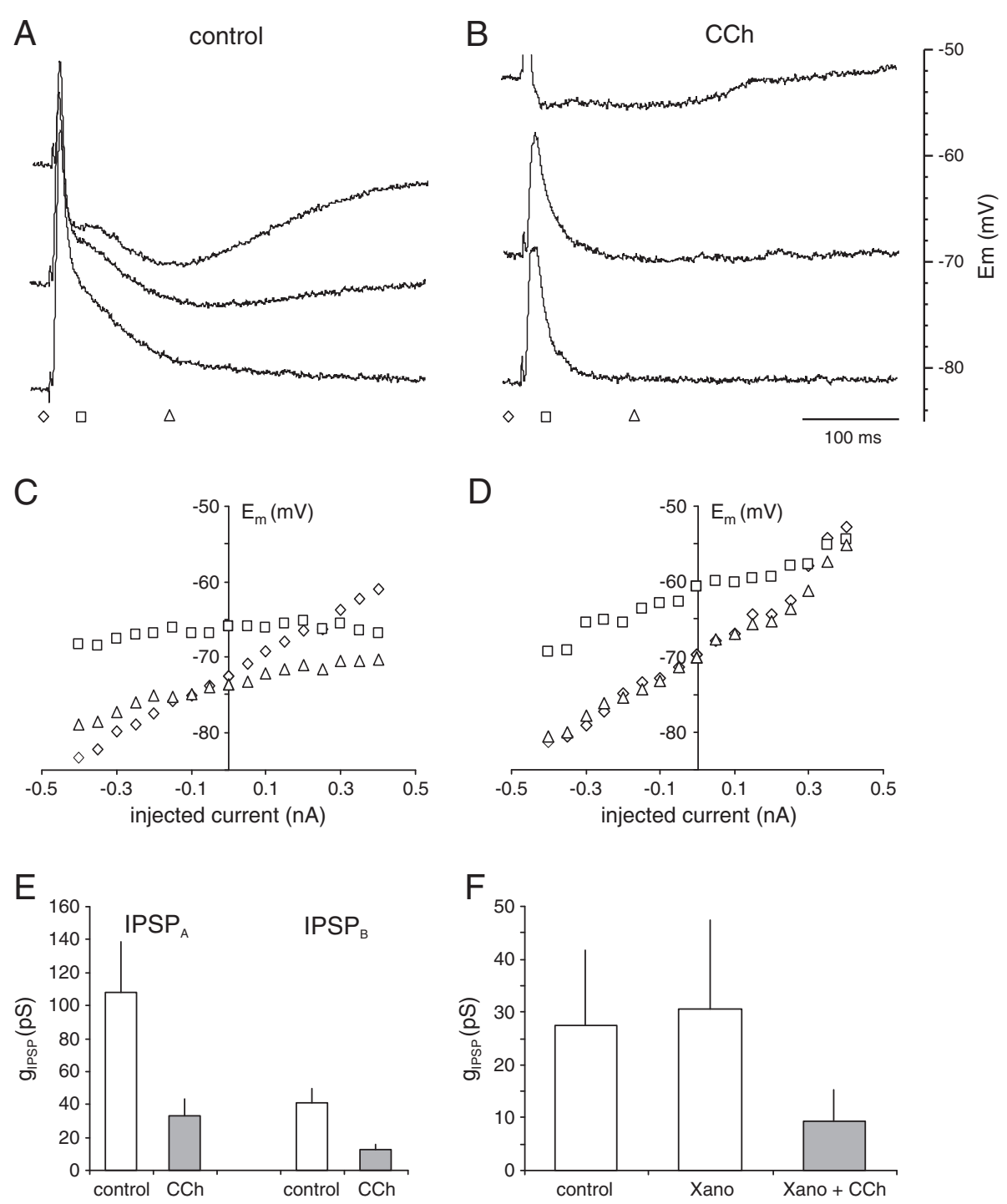

Figure 4 Effects of cholinergic compounds on synaptic inhibition. A, B. Voltage traces of a neurone in control conditions and in the presence of CCh. Orthodromic stimulation elicited compound synaptic responses consisting of an EPSP, IPSP A and IPSP. The two IPSPs are particularly obvious at less negative membrane potentials. The membrane potential was altered by current injections ( $+0.4,0,-0.4 \mathrm{nA}$, from top to bottom). B: Traces from the same neurone in the presence of CCh. Note the marked decrease in the amplitudes of IPSP $A$ and IPSP $P_{B}$ in the top trace. C,D: Plot of the membrane potentials obtained by different current injections ( -0.4 to $+0.4,0.05 \mathrm{nA}$ increment) at different times of the traces shown in $\mathrm{A}$ and $\mathrm{B}$. The different symbols denote the different times indicated in A and B. Note the decrease in IPSP and IPSP $\mathrm{B}_{\mathrm{B}}$ conductances obvious from the steeper current voltage relationship. E. Plot of the mean IIPSP-A $_{\text {and }}$ IPSP-B in control and in the presence of CCh as indicated. F. Plot of the mean gIPSP-B values in control, in the presence of xanomeline (xano) and xanomeline + CCh. The vertical bars represent the s.e.m.

APs/nA) and the depression of EPSP amplitudes (from $25.0 \pm 1.7$ to $23.8 \pm 1.2)$. Yet, the gIPSP-A and gIPSP-B were unaltered (control: $88 \pm 29 \mathrm{nS}, 28 \pm 7 \mathrm{nS}$, xanomeline: $92 \pm 28 \mathrm{nS}, 31 \pm 8 \mathrm{nS}$, respectively, $\mathrm{n}=5, p>0.05$, see Figure $4 \mathrm{~F}$ ). Addition of $10 \mu \mathrm{M} \mathrm{CCh}$ in the presence of xanomeline had no further effect on $\mathrm{E}_{\mathrm{m}}$ or $\mathrm{R}_{\mathrm{m}}(p>0.05 v s$. $\mathrm{CCh})$ but greatly reduced both inhibitory conductances, gIPSP-A decreased to $36 \pm 18 \mathrm{nS}$ and gIPSP-B to $9 \pm 3 \mathrm{nS}$, i.e. by 61.2 and $69.1 \%$, close to the values obtained for CCh alone. The difference to control was significant for gIPSP-B $(p<0.05)$, but just not significant for the $\mathrm{g}_{\text {IPSP-A }}$ $(p=0.057)$.

Modulation of glutamatergic transmission

Effects of carbachol on excitatory synaptic transmission: Field potentials and intracellular recordings

In control ACSF, the amplitudes of EPSP and field potentials increased progressively with increasing stimulus intensities to reach a plateau (Figure 5C, D). Application of CCh $(10 \mu \mathrm{M})$ decreased the amplitude of both 
A
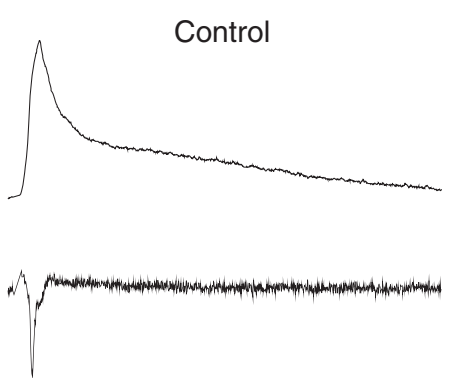

C

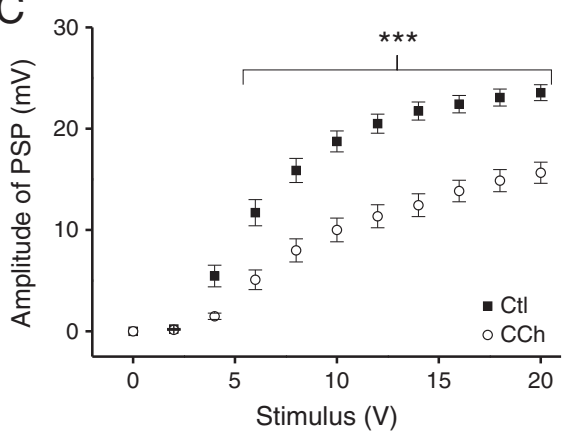

B
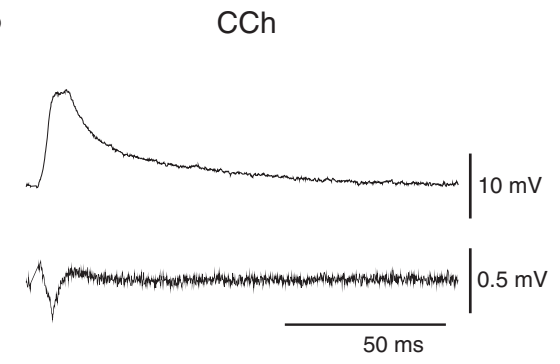

D

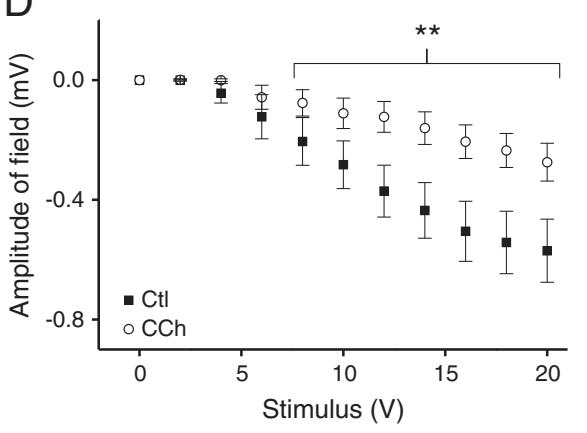

Figure $\mathbf{5}$ CCh-induced depression of synaptic transmission is due to activation of muscarinic receptors. A, B. Voltage traces of a rat neocortical neurone (top traces) and simultaneously recorded field potentials (bottom trace) in control condition (A) and in the presence of $10 \mu \mathrm{M}$ carbachol (CCh) (B). The traces show synaptic responses elicited by orthodromic stimulation (100 $\mu \mathrm{s}, 20 \mathrm{~V})$. Note the depressant effect of CCh on the amplitude of EPSP and field potential. C. Plot of the average EPSP amplitudes vs. stimulus intensity (input-output curve) in control conditions and in the presence of CCh as indicated $(n=45)$. D. Plot of the average field potential amplitudes vs. stimulus intensity in control and in the presence of CCh $(n=42)$. These experiments were performed in STRC. ${ }^{* *}: p<0.01,{ }^{* * *}: p<0.001$.

EPSP ( $\mathrm{n}=45, p<0.001$; Figure $5 \mathrm{~A}, \mathrm{~B}, \mathrm{C})$ and field potentials (STRC; $\mathrm{n}=42, p<0.05$; Figure $5 \mathrm{~A}, \mathrm{~B}, \mathrm{D}$ ) in a similar range of stimulus intensities.

The input-output curves of EPSP were well fitted by the Boltzmann equation yielding a maximal EPSP amplitude $\left(\mathrm{EPSP}_{\max }\right)$ of $22.6 \pm 0.9 \mathrm{mV}$, a half maximal stimulus intensity $\left(\mathrm{I}_{50}\right)$ of $6.71 \pm 0.36 \mathrm{~V}$ and a slope factor of $1.66 \pm 0.14(\mathrm{n}=45)$. CCh significantly decreased $\mathrm{EPSP}_{\max }$ to $16.0 \pm 1.1 \mathrm{mV}$ and increased both $\mathrm{I}_{50}$ and slope factor to $9.08 \pm 0.44 \mathrm{~V}$ and $2.82 \pm 0.24$, respectively $(\mathrm{n}=45 ; p<0.001)$, i.e. the curve became more shallow and $\mathrm{I}_{50}$ shifted to higher values.

The depression of field potentials by CCh $(n=8)$ was completely reversible ( $p>0.05 v s$. control), whereas that of EPSPs $(n=11)$ was partially reversible after washout. The EPSP $_{\max }$ recovered on average by $66 \pm 11 \%$ after washout $(p<0.05$ vs. control and CCh), whereas the effects on $\mathrm{I}_{50}$ and slope factor were completely reversible $(p>0.05$ vs. control, $\mathrm{n}=11)$.

\section{CCh-induced depression of synaptic responses is due to activation of mAChRs}

Atropine $(1 \mu \mathrm{M})$ alone had no effect on the amplitude of EPSP or field potentials at all stimulus intensities (2-20 V; $\mathrm{n}=9, p>0.05$; not shown). Also, $\mathrm{I}_{50}$ or slope factor were unaffected by atropine (not shown), indicating no obvious steady state modulation of synaptic responses by endogeneous mAChRs. Pre-application of atropine prevented the CCh-induced decrease of EPSP $_{\max }$ as well as the CChinduced increase of $\mathrm{I}_{50}$ and slope factor $(\mathrm{n}=7, p>0.05 v s$. atropine or $v s$. control; Table 1). Conversely, addition of atropine fully reversed the CCh-induced decrease of $\mathrm{EPSP}_{\text {max }}$ and field potential amplitude $(\mathrm{n}=7, p>0.05$ vs. control and $p<0.05$ vs. CCh; Table 1). The CCh-induced increase of $\mathrm{I}_{50}$ and slope factor were also reversed ( $\mathrm{n}=7, p>0.05$ vs. control and $p<0.05$ vs. CCh; Table 1). This suggests that the CCh effects on excitatory synaptic transmission are mediated by activation of mAChRs.

\section{The CCh-induced depression of synaptic responses is sensitive to pirenzepine and AFDX}

Applied alone, neither pirenzepine $(1 \mu \mathrm{M} ; \mathrm{n}=10)$ nor AFDX $(2 \mu M ; n=11)$ had detectable effects on the EPSP amplitude, $I_{50}$ or slope factor of the input-output curve (not shown; $p>0.05$ ).

Application of pirenzepine in the presence of $\mathrm{CCh}$ antagonized the CCh-induced decrease of EPSP $_{\max }$ $(\mathrm{n}=9, p>0.05 v s$. control and $p<0.05 v s$. CCh; Table 2). Pirenzepine also antagonized the increase of slope factor $(\mathrm{n}=9, p>0.05$ vs. control and $p<0.05$ vs. CCh) and 
Table 1 Effects of $10 \mu \mathrm{M} \mathrm{CCh}, 1 \mu \mathrm{M}$ atropine alone, or coapplication of $\mathrm{CCh}$ and atropine as indicated on the maximal amplitude of the field potentials, the maximal amplitude of EPSP (EPSP max $_{\text {) }}$, the $I_{50}$ and slope factor of the EPSP input-output curve

\begin{tabular}{|c|c|c|c|}
\hline & $\mathrm{Ctl}(\mathrm{n}=7)$ & $\operatorname{CCh}(n=7)$ & $\mathrm{CCh}+$ atro $(\mathrm{n}=7)$ \\
\hline Field max (mV) & $-0.53 \pm 0.17$ & $-0.16 \pm 0.05\left(^{*}\right)$ & $-0.61 \pm 0.15(+)$ \\
\hline EPSP max (mV) & $18.8 \pm 1.6$ & $11.8 \pm 1.6\left(^{*}\right)$ & $19.1 \pm 2.2(+)$ \\
\hline$I_{50}(V)$ & $7.25 \pm 1.15$ & $8.36 \pm 1.11\left(^{*}\right)$ & $6.39 \pm 1.13(+)$ \\
\hline \multirow[t]{2}{*}{ Slope factor } & $1.44 \pm 0.41$ & $2.75 \pm 0.2\left(^{*}\right)$ & $1.26 \pm 0.43(+)$ \\
\hline & Ctl $(n=7)$ & atro $(n=7)$ & atro $+\mathrm{CCh}(\mathrm{n}=7$ \\
\hline Field max (mV) & $-0.63 \pm 0.16$ & $-0.73 \pm 0.2\left(^{*}\right)$ & $-0.78 \pm 0.21\left(^{*}\right)$ \\
\hline EPSP max (mV) & $21 \pm 1.7$ & $21 \pm 1.8$ & $21.8 \pm 1.9$ \\
\hline$I_{50}(V)$ & $9.77 \pm 0.78$ & $9.5 \pm 0.8$ & $8.92 \pm 0.62$ \\
\hline Slope factor & $2.12 \pm 0.36$ & $2.05 \pm 0.29$ & $2.26 \pm 0.12$ \\
\hline
\end{tabular}

The order of two drugs given in the figures indicates the sequence of application (i.e. "CCh + atro" means atropine was added to a CCh containing ACSF and vice versa).

These experiments were performed in STRC

*: $p<0.05$ vs. control, $+: p<0.05$ vs. previous condition.

reduced the increase of $\mathrm{I}_{50}$ (CCh: $189 \pm 39 \%$ of control; $\mathrm{CCh}+$ Pir: $124 \pm 12 \%$ of control; $\mathrm{n}=9, p<0.05$ vs. control and CCh; Table 2). Application of pirenzepine prior to $\mathrm{CCh}$, however, failed to prevent the CCh-induced decrease of $\mathrm{EPSP}_{\text {max }}(\mathrm{n}=7, p<0.05 v s$. control or $v s$. pirenzepine alone; Table 2). In fact, $\mathrm{CCh}$ added to a pirenzepine-containing ACSF depressed the EPSP $\max$ to $76 \pm 6 \%$ of control $(n=7)$, indistinguishable from the depression observed with $\mathrm{CCh}$ alone (to $69 \pm 4 \%$ of the control; $\mathrm{n}=45 ; p>0.05)$. This failure of pirenzepine to prevent a CCh-induced depression, when applied before $\mathrm{CCh}$, is in sharp contrast to the pirenzepine effect on

Table 2 Effects of $10 \mu \mathrm{M}$ CCh, $1 \mu \mathrm{M}$ pirenzepine, or coapplication of $\mathrm{CCh}$ and pirenzepine, as indicated, on the maximal amplitude of the field potentials, the maximal amplitude of EPSP (EPSP ${ }_{\max }$ ), the $I_{50}$ and slope factor of the EPSP input-output curve

\begin{tabular}{|c|c|c|c|}
\hline & $\mathrm{Ctl}(\mathrm{n}=9)$ & $\mathrm{CCh}(\mathrm{n}=9)$ & $C C h+\operatorname{pir}(n=9)$ \\
\hline Field max (mV) & $-0.75 \pm 0.25$ & $-0.29 \pm 0.16\left(^{*}\right)$ & $-0.69 \pm 0.24(+)$ \\
\hline EPSP max (mV) & $24.3 \pm 1.5$ & $20.6 \pm 2\left(^{*}\right)$ & $23.6 \pm 1.7(+)$ \\
\hline$I_{50}(V)$ & $5.12 \pm 0.81$ & $9.23 \pm 1.71\left(^{*}\right)$ & $6.22 \pm 0.94\left(^{*}\right)(+)$ \\
\hline \multirow[t]{2}{*}{ Slope factor } & $1.61 \pm 0.59$ & $4.16 \pm 0.95\left(^{*}\right)$ & $1.52 \pm 0.40(+)$ \\
\hline & CtI $(n=7)$ & $\operatorname{pir}(n=7)$ & pir + CCh $(n=7$ \\
\hline Field max (mV) & $-0.68 \pm 0.3$ & $-0.7 \pm 0.29$ & $-0.56 \pm 0.25(+)$ \\
\hline EPSP max (mV) & $20.5 \pm 5.3$ & $20.3 \pm 5.1$ & $16.0 \pm 4\left(^{*}\right)(+)$ \\
\hline$I_{50}(V)$ & $8.41 \pm 0.75$ & $8.45 \pm 0.76$ & $9.37 \pm 1.04\left(^{*}\right)$ \\
\hline Slope factor & $1.93 \pm 0.54$ & $2.18 \pm 0.68$ & $1.95 \pm 0.31$ \\
\hline
\end{tabular}

The order of two drugs given in the figures indicates the sequence of application (i.e. " $\mathrm{CCh}+$ pir" means pirenzepine was added to a $\mathrm{CCh}$ containing ACSF and vice versa).

These experiments were performed in STRC.

*: $p<0.05$ vs. control, $+: p<0.05$ vs. previous condition. neuronal firing, where pirenzepine is effective irrespective of the sequence of application.

Application of AFDX in the presence of CCh partly antagonized the CCh-induced decrease of the EPSP $\max$ (by $52.3 \pm 3.1 \% ; \mathrm{n}=8, p<0.05$ vs. control and CCh; Table 3). AFDX did not antagonize the effect on $\mathrm{I}_{50}$ or slope factor $(\mathrm{n}=8, p>0.05 v s$. CCh and $p<0.05 v s$. control; Table 3). Also, application of AFDX before addition of CCh prevented the depressant effect of CCh on EPSPmax. Indeed, the EPSP $_{\text {max }}$ in the presence of AFDX $+\mathrm{CCh}$ was not different from that measured in the control condition ( $\mathrm{n}=7, p>0.05$; Table 3). Pre-application of AFDX also prevented the CCh-induced increase of $\mathrm{I}_{50}(p>0.05$ vs. control or AFDX alone) but not the increase of slope factor ( $\mathrm{n}=7, p<0.05 v s$. control or AFDX alone). To further determine which subtype of $\mathrm{mAChR}$ mediates the effects of CCh on EPSP, we applied xanomeline. Xanomeline decreased the EPSP $_{\max }$ from $25.6 \pm 1.8 \mathrm{mV}$ to $23.2 \pm 2.7 \mathrm{mV}(\mathrm{n}=12, p<0.05)$.

\section{CCh-induced depression of synaptic responses is not mimicked by M-current blockade}

Linopirdine had no effect on the amplitude of the field potentials (Figure 6A, B, bottom traces, 6D and only marginally decreased $(<10 \%)$ the amplitude of EPSP (Figure 6A, $\mathrm{B}$, top traces). This effect was only present at higher stimulus intensities ( $\mathrm{n}=12, p<0.05$; Figure $6 \mathrm{C}$ ). Linopirdine had no effect on the slope factor but slightly reduced $\mathrm{I}_{50}$ (from $6.9 \pm 0.6 \mathrm{~V}$ to $6.4 \pm 0.6 \mathrm{~V} ; \mathrm{n}=12, p<0.05)$. Retigabine $(10 \mu \mathrm{M})$ had no effect on the maximal amplitude of the field potentials (control: $-0.54 \pm 0.13 \mathrm{~V}$, retigabine: $-0.53 \pm 0.13 \mathrm{~V}$ ), on $\mathrm{EPSP}_{\max }$ (control: $30.8 \pm 3.4 \mathrm{~V}$, retigabine: $30.5 \pm 4.0 \mathrm{~V}$ ), or the slope factor (control: $1.01 \pm 0.26 \mathrm{~V}$,

Table 3 Effects of $10 \mu \mathrm{M}$ CCh, $2 \mu \mathrm{M}$ AFDX, or coapplication of CCh and AFDX as indicated on the maximal amplitude of the field potentials, the maximal amplitude of EPSP (EPSP $P_{\text {max }}$ ), the $I_{50}$ and slope factor of the EPSP input-output curve

\begin{tabular}{llll}
\hline & $\mathbf{C t I}(\mathbf{n}=\mathbf{8})$ & $\mathbf{C C h}(\mathbf{n}=\mathbf{8})$ & $\mathbf{C C h}+\mathbf{A F D X}(\mathbf{n}=\mathbf{8})$ \\
\hline Field max $(\mathbf{m V})$ & $-0.36 \pm 0.09$ & $-0.1 \pm 0.04\left(^{*}\right)$ & $-0.26 \pm 0.08\left(^{*}\right)(+)$ \\
EPSP max (mV) & $18.9 \pm 1.8$ & $10.9 \pm 1.6\left(^{*}\right)$ & $15.2 \pm 1.7\left(^{*}\right)(+)$ \\
$\mathbf{I}_{\mathbf{5 0}}(\mathbf{V})$ & $8.45 \pm 0.7$ & $10.9 \pm 0.86\left(^{*}\right)$ & $9.65 \pm 0.8\left(^{*}\right)$ \\
Slope factor & $2.29 \pm 0.27$ & $3.27 \pm 0.48\left(^{*}\right)$ & $2.70 \pm 0.33\left(^{*}\right)$ \\
& $\mathbf{C t I}(\mathbf{n}=\mathbf{7})$ & AFDX $(\mathbf{n}=\mathbf{7})$ & AFDX + CCh (n=7) \\
Field max (mV) & $-0.79 \pm 0.17$ & $-0.99 \pm 0.24$ & $-0.67 \pm 0.23$ \\
EPSP max (mV) & $22.2 \pm 2.4$ & $23.9 \pm 1.8\left(^{*}\right)$ & $23 \pm 1.8$ \\
$\mathbf{I}_{\mathbf{5 0}}(\mathbf{V})$ & $7.42 \pm 1.11$ & $7.22 \pm 1.44$ & $8.94 \pm 2.37$ \\
Slope factor & $1.82 \pm 0.67$ & $2.05 \pm 0.71$ & $3.07 \pm 0.75\left(^{*}\right)(+)$ \\
\hline
\end{tabular}

The order of two drugs given in the figures indicates the sequence of application (i.e. "CCh + AFDX" means AFDX was added to a CCh containing ACSF and vice versa).

These experiments were performed in STRC.

*: $p<0.05$ vs. control, $+: p<0.05$ vs. previous condition. 
A
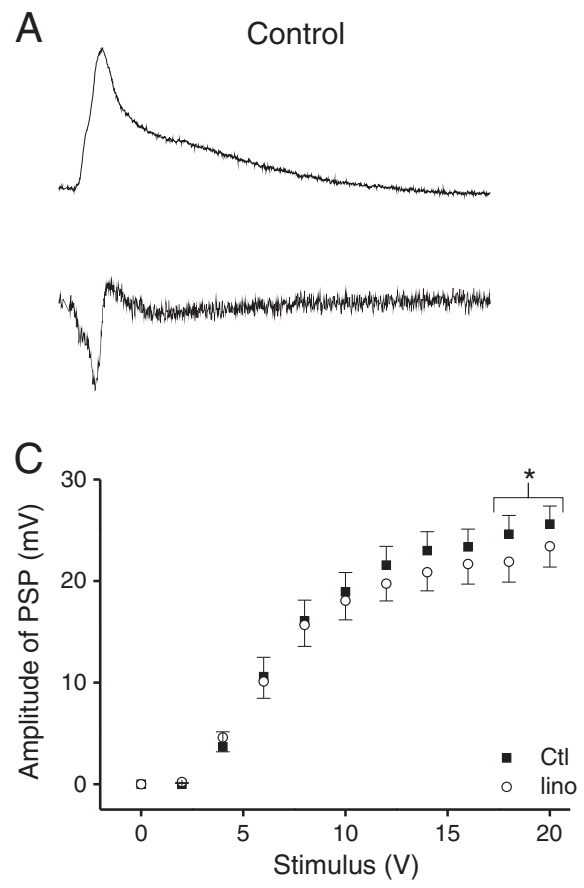

B
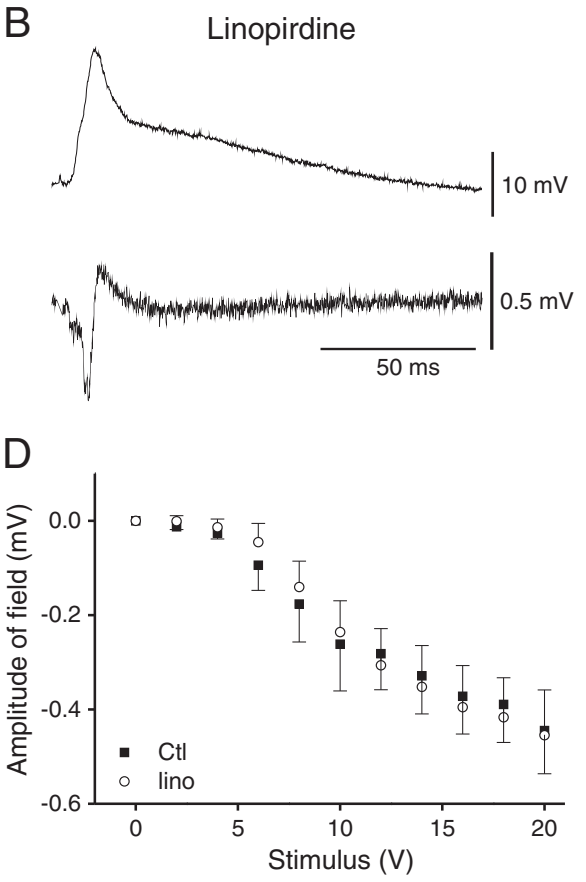

Figure $6 \mathbf{C C h}$-induced depression of synaptic transmission is not due to blockade of $\mathbf{M}$-current. A, B. Voltage traces (top traces) and field potentials (bottom traces) of a neocortical neurone in control condition (A) and in the presence of linopirdine (10 $\mu \mathrm{M})(B$; stimulus intensity $100 \mu \mathrm{s}, 20 \mathrm{~V})$. Note that linopirdine did not alter synaptic responses. C, D. Plots of average EPSP amplitudes $(C ; n=12)$ and field potentials (D; $\mathrm{n}=12$ ) vs. stimulus intensity in control and in the presence of linopirdine (lino) as indicated. Note that linopirdine application decreased the amplitude of EPSP only at the highest stimulus intensities. These experiments were performed in STRC. *: $p<0.05$.

retigabine: $1.12 \pm 0.24 \mathrm{~V})(\mathrm{n}=8, p>0.05$ for all). However, retigabine increased $\mathrm{I}_{50}$ (from $11.3 \pm 0.8 \mathrm{~V}$ to $13.2 \pm 0.9 \mathrm{~V}$; $\mathrm{n}=8, p<0.05)$. These data suggest that $\mathrm{CCh}$-induced depression of maximal field potentials and $\mathrm{EPSP}_{\max }$ are mediated by mAChRs not coupled to $\mathrm{K}_{\mathrm{V}} 7$ channels.

\section{Discussion}

The key findings of this study are: (i) activation of $M_{1}$ $\mathrm{mAChR}$ increased the neuronal AP firing via blockade of M-current, (ii) activation of $\mathrm{M}_{2} \mathrm{mAChR}$ increased the paired-pulse ratio of field potentials and decreased both components of GABAergic inhibition, and (iii) activation of $\mathrm{M}_{4} \mathrm{mAChR}$ depressed glutamatergic transmission presumably via activation of presynaptic receptors.

\section{Methodological aspects}

The previous studies investigating the mAChRs in slice preparations used either sharp microelectrode recordings $[20,30]$ or whole cell patch clamp recordings $[22,23,31,32]$. The latter disturb the intracellular milieu and a massive rundown of $\mathrm{M}$-current (modulated by mAChRs) was observed [33], precluding a reliable pharmacology. Intracellular recordings in cortical slices with sharp microelectrodes hence present a valuable method to quantify the effects at native mAChRs in slices.
However, reports in the neocortex focussed on the role of mAChRs or M-current either on the neuronal firing $[20,30,32]$, on the GABAergic transmission [23,31] or on the glutamatergic transmission $[22,34]$. Only few studies in cortex e.g. [21] or in hippocampus e.g. [35] investigated the role of mAChRs on both neuronal firing and synaptic transmission. The comparison of data obtained in different preparations using different experimental conditions is problematic, though. Therefore, in the present study we investigated the 3 aspects, namely change of firing, depression of EPSPs and of IPSPs, in the same preparation under identical experimental conditions.

Although some authors used different concentrations of mAChRs agonists/antagonists, only one or few stimulus intensities e.g. [22] or current injections e.g. [35] were used. Therefore, the results were mostly qualitative from a physiological point of view, precluding quantitative comparisons of different agonists/antagonists.

\section{Effect of mAChR activation on neuronal excitability}

The consistent increase in the slope of neuronal firing by $\mathrm{CCh}$ in the somatosensory cortex is similar to the hippocampus [35] and the nucleus gracilis [36]. However, our determination of slope and intercept provides a more quantitative analysis of changes of firing compared to previous observations $[35,36]$. In particular, these authors 
compared the neuronal firing in response to a single current intensity before and during substance application. The interpretation of such data would be complicated by concomitant alterations of membrane potential and/or neuronal input resistance.

In any case, alterations of firing are mediated by $\mathrm{mAChRs}$, as evidenced by the antagonism by atropine. Moreover, the antagonism by pirenzepine $\left(\mathrm{M}_{1} / \mathrm{M}_{4}\right.$ mAChRs antagonist) but not by AFDX $\left(\mathrm{M}_{2} / \mathrm{M}_{4} \mathrm{mAChRs}\right.$ antagonist) further suggests an effect via $M_{1} m A C h R$, similar to the $M_{1} m A C h R$-mediated repetitive spontaneous neuronal firing observed in rat prefrontal cortex [21]. Our conclusion is in line with previous data indicating that $\mathrm{ACh}$ application increases the neuronal firing of neocortical pyramidal neurones in mice lacking $\mathrm{M}_{3}$ or $\mathrm{M}_{5} \mathrm{mAChRs}$ but not in mice lacking $\mathrm{M}_{1} \mathrm{mAChR}$, confirming further an involvement of the $\mathrm{M}_{1} \mathrm{mAChR}$ in this effect [37].

The cellular mechanisms underlying the CCh-induced increase of AP firing can be inferred from the effect of linopirdine which is an established blocker of $\mathrm{K}_{\mathrm{V}} 7$ channels [25]. Linopirdine increased the neuronal firing as in hippocampus [25] and entorhinal cortex [32]. Together, these data indicate a $\mathrm{M}_{1} \mathrm{mAChR}$ mediated depression of M-current [38] as the underlying mechanism of CChinduced firing increase.

\section{Effect of mAChR activation on GABAergic transmission}

We studied the $\mathrm{mAChR}$ mediated effect on neurotransmitter release by using the paired-pulse protocol with field potentials. CCh increased the PPR for interpulse intervals ranging from 10 to $400 \mathrm{~ms}$. This suggests that the $\mathrm{CCh}$ effect involves both $\mathrm{GABA}_{\mathrm{A}}$ and $\mathrm{GABA}_{\mathrm{B}}$ receptor-mediated effects. The $\mathrm{CCh}$-induced increase of the PPR is most likely due to mAChR-mediated depression of GABA release [23], and evoked IPSCs [31], during the first stimulus. Normally, GABA would attenuate the response to a second stimulus by decreasing release via presynaptic $\mathrm{GABA}_{B}$ receptors $[39,40]$. Hence a mAChRmediated depression of GABA release might contribute to the altered paired pulse properties of synaptic responses.

The involvement of $\mathrm{M}_{2} \mathrm{mAChR}$ in the CCh-induced depression of GABA release underlying increase of PPR can be inferred from the antagonism by AFDX $\left(\mathrm{M}_{2} / \mathrm{M}_{4} \mathrm{mAChRs}\right.$ antagonist $)$ and lack of antagonism by pirenzepine $\left(M_{1} / M_{4} m A C h R s\right.$ antagonist). Similar to the pharmacology at $\mathrm{M}_{1} \mathrm{mAChR}$, the effects of atropine and AFDX on this $\mathrm{M}_{2} \mathrm{mAChR}$-mediated increase of PPR were identical whether the antagonist was applied in the presence of, or before, CCh.

Further evidence was obtained by evaluating the alterations in inhibitory conductance mediated by $\mathrm{GABA}_{\mathrm{A}}$ and $\mathrm{GABA}_{\mathrm{B}}$ receptors. Firstly, the similarity in the depression of both $g_{\text {IPSP-A }}$ and $\mathrm{g}_{\text {IPSP-B}}$, indicates a common denominator for both effects i.e. depression of GABA release. The effects of the selected compounds revealed which $\mathrm{mAChR}$ is involved in this depression of GABA release. The $\mathrm{CCh}$ effects were considerably antagonized by the $\mathrm{M}_{2} / \mathrm{M}_{4} \mathrm{mAChRs}$ antagonist AFDX but slightly by the $\mathrm{M}_{1} / \mathrm{M}_{4} \mathrm{mAChRs}$ antagonist pirenzepine. Moreover, the $\mathrm{M}_{1} / \mathrm{M}_{4} \mathrm{mAChRs}$ agonist xanomeline had no effects on $\mathrm{g}_{\text {IPSP-A }}$ or $\mathrm{g}_{\text {IPSP-B}}$, yet subsequent addition of CCh reduced $\mathrm{g}_{\text {IPSP-A }}$ and $\mathrm{g}_{\text {IPSP. }}$. This observation strongly suggests that neither $\mathrm{M}_{1}$ nor $\mathrm{M}_{4} \mathrm{mAChRs}$ are involved in the modulation of GABA release. Together these data support our view that $M_{2} m A C h R$ are involved in the modulation of GABA release.

This view is also supported by histological data. $\mathrm{M}_{2}$ mAChRs are predominantly localized at presynaptic axons of GABAergic neurones and are associated with asymmetric as well as symmetric cortical synapses [16$18,23]$, suggesting that $M_{2} m A C h R$ can modulate GABA release in the neocortex. In addition, $\mathrm{M}_{1} \mathrm{mAChRs}$ are mainly expressed on cortical pyramidal neurones rather than by GABAergic neurones [41].

$A C h$ reduces the GABA release in neocortex by two separate mechanisms i) by decreasing $\mathrm{Ca}^{2+}$ currents via activation of a $\mathrm{M}_{2} \mathrm{mAChR} / \mathrm{PI} 3 \mathrm{~K} / \mathrm{Ca}^{2+}$-independent PKC pathway and to a smaller extent by activation of a $\mathrm{M}_{1}$ $\mathrm{mAChR} / \mathrm{PLC} / \mathrm{Ca}^{2+}$-dependent PKC pathway [23]. This combination might explain the relatively large contribution of the $\mathrm{M}_{2} \mathrm{mAChR}$ and the absence of detectable effects of the $M_{1} m A C h R$ in the CCh-induced increase of PPR observed here.

\section{Effect of mAChR activation on glutamatergic transmission}

Our observation of CCh decreasing the amplitudes of evoked synaptic potentials is in line with a wealth of evidence from various areas of the rodent brain [22,34-36]. Both field potentials and intracellularly recorded EPSPs were depressed by $\mathrm{CCh}$ to a similar degree. Considering the marginal changes in $E_{m}$, this decrease cannot be accounted for by a membrane depolarization, confirming results obtained in entorhinal cortex [34]. These authors reported that the depression of synaptic transmission persisted when neurones were returned to their initial resting potential. However, previous observations in hippocampus e.g. [35] or neocortex e.g. [21,22] compared the synaptic response following a single stimulus intensity before and during substance application. Our determination of $\mathrm{I}_{50}, \mathrm{EPSP}_{\max }$ and slope factor provide a more quantitative analysis of changes of synaptic transmission, corroborating and extending previous findings. In particular, the consistent effects over a wide range of stimulus intensities exclude the possibility of threshold phenomena.

Our data indicate that this CCh-induced depression of EPSP is 1) fully prevented when CCh is applied in the 
presence of atropine or AFDX and 2) only partially prevented when $\mathrm{CCh}$ was applied in the presence of pirenzepine. This corroborates and extends previous data from layer $\mathrm{V}$ of the somatosensory cortex [22]. Unlike these authors, applying $\mathrm{CCh}$ in the presence of antagonists, we also applied the mAChRs antagonists in the presence of $\mathrm{CCh}$, revealing marked differences with different sequence of application. The CCh-mediated depression of EPSP was fully reversed when pirenzepine or atropine was added in the presence of $\mathrm{CCh}$, i.e. pirenzepine is more effective when applied in the presence of the agonist. AFDX, however, only partially reversed this depression, i.e. is less effective when applied in the presence of the agonist. This peculiarity may contribute to the discrepancies between previous reports. Usually, the authors have either applied the antagonist in the presence of agonist or vice versa, the agonist in the presence of antagonists. To the best of our knowledge, the two complementary protocols had not been used in the same study so far e.g. either addition or pre-application was used, see $[22,42]$.

We propose that pirenzepine, a $M_{1} / M_{4}$ prefering mAChRs antagonist [43], affects the EPSP amplitude via $\mathrm{M}_{4} \mathrm{mAChR}$ for the following reasons:

1) The increase of neuronal firing by $\mathrm{CCh}$ was prevented and reversed by pirenzepine. However, the decrease of $\mathrm{EPSP}_{\max }$ by $\mathrm{CCh}$ was reversed but not prevented by pirenzepine. This difference may suggest that the pirenzepine-sensitive effects on EPSP $_{\text {max }}$ and on slope of neuronal firing are mediated by two distinct $\mathrm{mAChRs}$, i.e. the pirenzepine-sensitive effect on EPSP $_{\max }$ is not mediated by $\mathrm{M}_{1} \mathrm{mAChR}$.

2) Only $M_{2}$ and $M_{4} m A C h R s$ (but not $M_{1}, M_{3}$ and $M_{5}$ mAChRs) are coupled to G-proteins $G_{i} / G_{o}$ family involved in the inhibition of neurotransmitter release $[7,44,45]$. In addition, recent evidence indicates that $M_{4}$ $\mathrm{mAChR}$ is the major mAChR subtype responsible for direct cholinergic modulation of EPSP [46]. Therefore, the pirenzepine effect on CCh-induced EPSP depression is probably due to an action of pirenzepine on $\mathrm{M}_{4}$ rather than $M_{1}$ mAChRs [43]. This view is supported by immunohistochemical data [17], showing that cortical $M_{1}$ $\mathrm{mAChRs}$ are located exclusively at postsynaptic sites.

3) The effects of atropine and AFDX on the $M_{2}$ mAChR-mediated increase of PPR were identical regardless of the sequence of application. However, the effects of pirenzepine and AFDX on the CCh-induced decrease of EPSP were different whether this antagonist is applied in the presence or before the CCh application. This difference may suggest that the CCh-induced decrease of EPSP $_{\text {max }}$ and increase of PPR are mediated by two distinct $\mathrm{mAChRs}$, i.e. the CCh-induced decrease of EPSP $\max$ is not mediated by $\mathrm{M}_{2} \mathrm{mAChR}$. Moreover, the increase of PPR by $\mathrm{CCh}$ (mediated by $\mathrm{M}_{2} \mathrm{mAChR}$ ) was not prevented or reversed by pirenzepine. This suggests that pirenzepine is not active at $\mathrm{M}_{2} \mathrm{mAChR}$ in our conditions.

4) AFDX applied before CCh or pirenzepine applied in the presence of $\mathrm{CCh}$ can both fully prevent and reverse, respectively, the CCh-induced depression of $\mathrm{EPSP}_{\max }$. The similar potency of pirenzepine and AFDX on CChinduced $\mathrm{EPSP}_{\max }$ depression therefore suggests an involvement of $\mathrm{M}_{4} \mathrm{mAChR}$ as the most parsimonious explanation.

\section{Cholinergic transmission and cognition}

Ample evidence suggests that mAChR-mediated signalling in the cortex is critical for learning and memory, yet the mechanisms of ACh facilitating cognitive processes remained elusive. The effects reported here, namely the depression of EPSP and the increased neuronal firing mediated by different mAChRs would provide a very interesting system for "attention" at the cellular level. The $\mathrm{M}_{4}$ mAChR-mediated depression of EPSP reduces the noise of ongoing synaptic activity while the $M_{1}$ mAChR-mediated increase of neuronal firing augments the neuronal response to a given synaptic input, i.e. these two effects would improve the signal to noise ratio. Moreover, the shallower input-output curve of synaptic responses induced by $\mathrm{M}_{4} \mathrm{mAChR}$ observed here extends the subthreshold range for temporal summation, which is augmented by a CCh-induced reduction of Kir-type potassium current [21]. In addition, the cholinergic depression of GABA release corresponds to a depression of inhibition by higher frequencies of stimulation [40] implicated in long-term potentiation [47]. Together, these data corroborate and extend a theoretical framework proposed by Hasselmo and McGaughy [48].

\section{Conclusions}

Our data provide evidence that the triade of cellular CCh effects are mediated by three subtypes of mAChR, i) $M_{1}$ mAChR-mediated increase of firing, ii) $M_{2}$ mAChR-mediated depression of GABA release and iii) $\mathrm{M}_{4}$ mAChR-mediated depression of glutamatergic synaptic responses. Activation of these effects by physiologically released ACh provides an interesting combination of neuronal attention and facilitation of LTP. In addition, the three parameters delineated here may present useful tools to test new $\mathrm{M}_{1}, \mathrm{M}_{2}$ or $\mathrm{M}_{4}$ mAChRs modulators at native receptors in the human neocortex from epilepsy surgery tissues.

\section{Methods}

\section{Tissue handling and preparation}

Coronal slices containing the sensorimotor cortex were made from male Wistar rats (age: 30-42 d). Experiments were approved by the Berlin health protection agency 
( $\mathrm{T}$ 026/96). Rats were deeply anesthetized with ether, decapitated and a block of brain containing the sensorimotor cortex was quickly removed. The tissue was cut into slices $(400 \mu \mathrm{m})$ with a vibratome (HM $650 \mathrm{~V}$, MICROM International, Walldorf, Germany) in artificial cerebrospinal fluid (ACSF, $5 \pm 1^{\circ} \mathrm{C}$ ). The slices were stored submerged at room temperature in continuously oxygenated (carbogen: 95\% $\mathrm{O}_{2}-5 \% \mathrm{CO}_{2}$ ) ACSF. Slices were allowed to recover for at least 1 hour before recordings commenced. Individual slices were transferred to the recording chambers and given $30 \mathrm{~min}$ to adapt.

\section{Solutions and substances}

ACSF contained (in mM) $124 \mathrm{NaCl}, 5 \mathrm{KCl}, 2 \mathrm{MgSO}_{4}, 2$ $\mathrm{CaCl}_{2}, 1.25 \mathrm{NaH}_{2} \mathrm{PO}_{4}, 26 \mathrm{NaHCO}_{3}$ and 10 glucose $(\mathrm{pH}$ 7.4, after equilibration with carbogen).

Atropine (Sigma, Taufkirchen, Germany), carbamylcholine-chloride (carbachol, CCh; Gift from GlaxoSmithKline), linopirdine dihydrochloride (Tocris, Bristol, UK) and pirenzepine (Sigma) were dissolved in $\mathrm{H}_{2} \mathrm{O}$. AF-DX 116 (abbreviated AFDX, Tocris), retigabine and xanomeline (both gift from GlaxoSmithKline) were dissolved in DMSO. The final concentration of DMSO was below $0.1 \%$. Stock solutions of each drug were prepared and stored at $-20^{\circ} \mathrm{C}$ until use.

The following mAChRs related compounds were used: pirenzepine $\left(\mathrm{M}_{1} / \mathrm{M}_{4} \mathrm{mAChRs}\right.$ antagonist), AFDX 116 $\left(\mathrm{M}_{2} / \mathrm{M}_{4}\right.$ mAChRs antagonist), xanomeline $\left(\mathrm{M}_{1} / \mathrm{M}_{4}\right.$ $\mathrm{mAChRs}$ agonist) and atropine (broad spectrum mAChRs antagonist) $[24,43,49]$. We refrained from using mamba toxin 7 , a proposed selective blocker of $M_{1}$ $\mathrm{mAChR}$, because the application via perfusion would be prohibitively expensive and the stability under our recording conditions (oxygen, $32^{\circ} \mathrm{C}$ ) is uncertain [communicated by a manufacturer]. We chose established concentrations of agonist and antagonist based on a literature survey and a few pilot experiments. A concentration of $10 \mu \mathrm{M}$ CCh and $1 \mu \mathrm{M}$ atropine is established in slices [21,22], and at $1 \mu \mathrm{M}$, atropine does not interfere with nicotinic receptors [50]. The concentrations of pirenzepine $(1 \mu \mathrm{M})$ and AFDX $(2 \mu \mathrm{M})$ were chosen from binding experiments $[43,49]$ and are effective on the CCh-induced depression of PSP in neocortex or hippocampus slices for example [22,51]. Pirenzepine at $1 \mu \mathrm{M}$ should have a maximal effect at $M_{1}$ and $M_{4}$ mAChRs but not at $M_{2}, M_{3}$ and $M_{5}$ mAChRs. AFDX at $2 \mu \mathrm{M}$ should have a maximal effect at $M_{2}$ and $M_{4}$ mAChRs but not at $M_{1}, M_{3}$ and $M_{5}$ mAChR [49].

From the above considerations, the following predictions can be made with a minimum of compounds: 1) a $\mathrm{M}_{1}$ mAChR-mediated effect should be antagonized by pirenzepine but not by AFDX, 2) a $\mathrm{M}_{2}$ mAChR-mediated effect should be antagonized by AFDX but not by pirenzepine and 3) a $\mathrm{M}_{4} \mathrm{mAChR}$-mediated effect should be antagonized by either pirenzepine or AFDX.
To reveal more subtle pharmacological differences of the mAChRs, i.e. effects of activation state, we applied antagonists either before or during the CCh application.

\section{Electrophysiological recordings Recording chambers}

Experiments were carried out either in an interface-type recording chamber (ITRC) or in a submersion-type recording chamber (STRC). The ITRC enables maximal oxygen supply and improves recordings of evoked field potentials and was therefore chosen for the paired-pulse protocol. The STRC provides more stable conditions and allows a faster equilibration of drugs in the slices [28]. Therefore, STRC was chosen for intracellular recordings.

In ITRC, slices were perfused with oxygenated ACSF $\left(1.5-2 \mathrm{ml} / \mathrm{min} ; 34 \pm 1^{\circ} \mathrm{C}\right)$ and the atmosphere was maintained by a continuous flow of pre-warmed and humidified carbogen. In STRC experiments slices were held between two nylon grids and perfused with a higher flow rate of oxygenated ACSF (4-5 ml/min; $31 \pm 1^{\circ} \mathrm{C}$ ).

All measurements were made at least $30 \mathrm{~min}$ (ITRC) or 15 min (STRC) after drug application to ascertain steady-state of applied drugs.

\section{Electrodes}

For extracellular recordings, filamented borosilicate capillaries (Hilgenberg, Malsfeld, Germany) were pulled on a DMZ universal puller (Zeitz, München, Germany). The pipette resistances were 2-8 M $\Omega$ when filled with ACSF. Sharp microelectrodes for intracellular recordings were pulled on a Flaming/Brown P87 Puller (Sutter Instruments, Novato, U.S.A.). When filled with $1 \mathrm{M}$ potassium acetate ( $\mathrm{pH} 7.2$, containing also $1 \mathrm{mM} \mathrm{KCl}$ and $5 \mathrm{mM}$ EGTA) the electrodes had resistances between 70 and $120 \mathrm{M} \Omega$.

\section{Extra- and intracellular recordings}

The electrodes were positioned under visual control in neocortical layers II/III. Signals obtained with extracellular recordings were fed to a high-impedance preamplifier (EXT-01 C, npi electronic, Tamm, Germany) and processed through second-stage amplifiers with filtering capabilities (DPA 2 F; npi electronic, Tamm, Germany). The signals obtained with intracellular recordings were fed to an appropriate amplifier (SEC-05 L, npi electronic, Tamm, Germany).

We evaluated the current voltage relationship from families of current injections (between $-0.5 \mathrm{nA}$ and $+1.5 \mathrm{nA}$, increment $0.05 \mathrm{nA}$, duration $600 \mathrm{~ms}$ ), to estimate the neuronal input resistance and the firing behaviour. Linear regression of the number of APs $v s$. injected current in the initial linear range was used to calculate the slope and the intercept. The former parameter provides a quantitative index of AP firing behaviour in a 
given condition. The latter represents the current just below the rheobase and was termed sub-rheobase.

Synaptic responses were elicited by electrical stimuli (0-20 V, increment $2 \mathrm{~V}, 100 \mu$ s duration at $0.1 \mathrm{~Hz}$, in triplicate) applied via a bipolar tungsten electrode placed in the deeper cortical layers (V/VI). The peak amplitude of the initial component represents the excitatory postsynaptic potential and will be referred to as EPSP, although it might be slightly affected by the inhibitory postsynaptic potential (IPSP) with a slightly later time to peak (see Figure 4A). The input-output curves of EPSP were fitted by the Boltzmann equation:

$$
\mathrm{Y}=\left(\mathrm{A}_{1}-\mathrm{A}_{2}\right) /\left(1+\mathrm{e}^{(\mathrm{x}-\mathrm{xo}) / \mathrm{dx}}\right)+\mathrm{A}_{2}
$$

yielding the maximal EPSP amplitude $\left(\mathrm{A}_{2}, \mathrm{EPSP}_{\max }\right)$, the half maximal stimulus $\left(\mathrm{x}_{0}, \mathrm{I}_{50}\right)$ and the slope factor $(\mathrm{dx})$.

Synaptic conductance mediated by $\mathrm{GABA}_{\mathrm{A}}$ and $\mathrm{GABA}_{\mathrm{B}}$ receptors was estimated similar to previous methods [40,52]. In brief, linear regressions of the current voltage relation (usually between -0.3 and +0.3 $\mathrm{nA}$ ) was carried out before the stimulus and at the apparent peak of the early and late inhibitory synaptic responses (near $20 \mathrm{~ms}$ and $150 \mathrm{~ms}$ poststimulus). Assuming synaptic conductances parallel to "resting" membrane conductance, the subtraction of resting membrane conductance from the total conductance at the peak of $\mathrm{GABA}_{\mathrm{A}}$ and $\mathrm{GABA}_{\mathrm{B}}$ receptor-mediated events yields an estimate for the two synaptic responses see [40].

To evaluate the effects of $\mathrm{mAChR}$ agonists/antagonists on neurotransmitter release supposedly via presynaptic sites, we recorded the field potentials during a pairedpulse protocol in an ITRC. The ratio of amplitude of the second field potential in relation to the first in response to identical stimulations $(100 \mu \mathrm{s}, 1 \mathrm{~mA})$ was calculated for different interstimulus intervals (10 ms-1 s) and was termed paired-pulse ratio (PPR). An intensity of $1 \mathrm{~mA}$ was chosen for this protocol since it induced a maximal response with pronounced paired-pulse depression in all slices tested. In addition, we performed input-output curves, as in STRC. In ITRC, field potentials were elicited in cortical layers II/III by electrical stimuli (0-1 mA, increment $0.1 \mathrm{~mA}, 100 \mu \mathrm{s}$ duration at $0.1 \mathrm{~Hz}$, in triplicate) delivered via a bipolar tungsten electrode placed in cortical layers V/VI.

\section{Data acquisition and analysis}

Recorded signals were digitized on-line $(10 \mathrm{kHz})$ with a PC based system (Digidata 1200 and Clampex 9.3 or Digidata $1440 \mathrm{~A}$ and Clampex 10.1 software, Molecular Devices, Sunnyvale CA, USA), stored on hard disk and analysed off-line (Clampfit 10.1).
Our intracellular recordings were from "regular firing" neurones, as opposed to "fast spiking" or "burst firing" neurones [53].

Data are presented as mean \pm s.e.m., $\mathrm{n}$ indicates the number of cells (only one cell per slice was recorded). For comparisons, we used paired or unpaired Student's $t$-test. Differences with $p<0.05$ were considered significant.

\section{Abbreviations}

ACh: Acetylcholine; ACSF: Artificial cerebrospinal fluid; AFDX: AF-DX 116; CCh: Carbamylcholine-chloride (carbachol); $E_{m}$ : Resting membrane potential; EPSP: Excitatory postsynaptic potentials; IPSP: Inhibitory postsynaptic potentials; ITRC: Interface-type recording chamber; LTP: Long term potentiation; mAChR: Muscarinic acetylcholine receptor; PPR: Paired-pulse ratio; $R_{m}$ : Input resistance; STRC: Submersion-type recording chamber.

\section{Acknowledgements}

We are most grateful to R. Fleischmann, who did some of the recordings with pirenzepine application. The study was made possible by a grant from G.S.K.

\section{Author details}

${ }^{1}$ Center for Anatomy, Institute for Cell Biology and Neurobiology, Charité Universitätsmedizin Berlin, Philippstr. 12, 10115 Berlin, Germany.

${ }^{2}$ GlaxoSmithKline, Centre of Excellence for Drug Discovery, Third Avenue, Harlow, Essex CM19 5AW, UK.

\section{Authors' contributions}

S.G. and R.A.D. did the experiments, data analysis and writing of the manuscript. S.W. assisted during the experiments and provided helpful comments on the manuscript. G.A.J. C.H.D. and J.M.W. initiated these experiments and commented on a preliminary version of the manuscript.

Received: 21 December 2011 Accepted: 27 April 2012

Published: 27 April 2012

\section{References}

1. Wess J: Muscarinic acetylcholine receptor knockout mice: novel phenotypes and clinical implications. Annu Rev Pharmacol Toxicol 2004, 44:423-450.

2. Freedman R, Adler LE, Bickford P, Byerley W, Coon H, Cullum CM, Griffith JM, Harris JG, Leonard S, Miller C, et al: Schizophrenia and nicotinic receptors. Harv Rev Psychiatry 1994, 2(4):179-192.

3. Harbaugh RE, Roberts DW, Coombs DW, Saunders RL, Reeder TM: Preliminary report: intracranial cholinergic drug infusion in patients with Alzheimer's disease. Neurosurgery 1984, 15(4):514-518.

4. Minzenberg MJ, Poole JH, Benton C, Vinogradov S: Association of anticholinergic load with impairment of complex attention and memory in schizophrenia. Am J Psychiatry 2004, 161(1):116-124.

5. Fisher $A$ : Cholinergic treatments with emphasis on $m_{1}$ muscarinic agonists as potential disease-modifying agents for Alzheimer's disease. Neurotherapeutics 2008, 5(3):433-442.

6. Pepeu G, Giovannini MG: Cholinesterase inhibitors and beyond. Curr Alzheimer Res 2009, 6(2):86-96.

7. Caulfield MP, Birdsall NJM: International union of pharmacology. XVII. Classification of muscarinic acetylcholine receptors. Pharmacol Rev 1998, 50(2):279-290.

8. Peralta EG, Ashkenazi A, Winslow JW, Smith DH, Ramachandran J, Capon DJ: Distinct primary structures, ligand-binding properties and tissue-specific expression of 4 human muscarinic acetylcholine-receptors. EMBO J 1987, 6(13):3923-3929.

9. Delmas P, Brown DA: Pathways modulating neural KCNQ/M (Kv7) potassium channels. Nat Rev Neurosci 2005, 6(11):850-862.

10. Langmead CJ, Watson J, Reavill C: Muscarinic acetylcholine receptors as CNS drug targets. Pharmacol Ther 2008, 117(2):232-243.

11. Clader JW, Wang Y: Muscarinic receptor agonists and antagonists in the treatment of Alzheimer's disease. Curr Pharm Des 2005, 11(26):3353-3361. 
12. Olianas MC, Dedoni S, Ambu R, Onali P: Agonist activity of Ndesmethylclozapine at delta-opioid receptors of human frontal cortex. Eur J Pharmacol 2009, 607(1-3):96-101.

13. Fleming JJ, England PM: Developing a complete pharmacology for AMPA receptors: a perspective on subtype-selective ligands. Bioorg Med Chem 2010, 18(4):1381-1387.

14. Thomas DR, Dada A, Jones GA, Deisz RA, Gigout S, Langmead CJ, Werry TD, Hendry N, Hagan JJ, Davies $\mathrm{CH}$, et al: N-desmethylclozapine (NDMC) is an antagonist at the human native muscarinic $\mathrm{M}_{1}$ receptor. Neuropharmacology 2010, 58(8):1206-1214

15. Levey Al, Kitt CA, Simonds WF, Price DL, Brann MR: Identification and localization of muscarinic acetylcholine receptor proteins in brain with subtype-specific antibodies. J Neurosci 1991, 11(10):3218-3226.

16. Mrzljak L, Levey Al, Belcher S, Goldman-Rakic PS: Localization of the $m_{2}$ muscarinic acetylcholine receptor protein and mRNA in cortical neurons of the normal and cholinergically deafferented rhesus monkey. J Comp Neurol 1998, 390(1):112-132.

17. Mrzljak L, Levey Al, Goldman-Rakic PS: Association of $m_{1}$ and $m_{2}$ muscarinic receptor proteins with asymmetric synapses in the primate cerebral cortex: morphological evidence for cholinergic modulation of excitatory neurotransmission. Proc Natl Acad Sci USA 1993, 90(11):51945198.

18. Disney AA, Domakonda KV, Aoki C: Differential expression of muscarinic acetylcholine receptors across excitatory and inhibitory cells in visual cortical areas V1 and V2 of the macaque monkey. J Comp Neurol 2006, 499(1):49-63.

19. Krnjevic K, Pumain R, Renaud L: The mechanism of excitation by acetylcholine in the cerebral cortex. J Physiol (Lond) 1971, 215(1):247-268.

20. McCormick DA, Williamson A: Convergence and divergence of neurotransmitter action in human cerebral cortex. Proc Natl Acad Sci USA 1989, 86(20):8098-8102.

21. Carr DB, Surmeier DJ: $M_{1}$ muscarinic receptor modulation of Kir2 channels enhances temporal summation of excitatory synaptic potentials in prefrontal cortex pyramidal neurons. J Neurophysiol 2007, 97(5):3432-3438.

22. Levy RB, Reyes $A D$, Aoki $C$ : Nicotinic and muscarinic reduction of unitary excitatory postsynaptic potentials in sensory cortex; Dual intracellular recording in vitro. J Neurophysio/ 2006, 95(4):2155-2166.

23. Salgado $H$, Bellay $T$, Nichols JA, Bose M, Martinolich L, Perrotti L, Atzori M Muscarinic $\mathrm{M}_{2}$ and $\mathrm{M}_{1}$ receptors reduce $\mathrm{GABA}$ release by $\mathrm{Ca}^{2+}$ channel modulation through activation of $\mathrm{PI} 3 \mathrm{~K} / \mathrm{Ca}^{2+}$-independent and $\mathrm{PLC} / \mathrm{Ca}^{2}$ +-dependent PKC. J Neurophysio/ 2007, 98(2):952-965.

24. Shannon HE, Rasmussen K, Bymaster FP, Hart JC, Peters SC, Swedberg MDB, Jeppesen L, Sheardown MJ, Sauerberg P, Fink-Jensen A: Xanomeline, an $M_{1} / M_{4}$ preferring muscarinic cholinergic receptor agonist, produces antipsychotic-like activity in rats and mice. Schizophrenia Research 2000, 42(3):249-259.

25. Aiken SP, Lampe BJ, Murphy PA, Brown BS: Reduction of spike frequency adaptation and blockade of $\mathrm{M}$-current in rat $\mathrm{CA} 1$ pyramidal neurones by linopirdine (DuP 996), a neurotransmitter release enhancer. $\mathrm{Br} \mathrm{J}$ Pharmacol 1995, 115(7):1163-1168.

26. Rundfeldt C: The new anticonvulsant retigabine (D-23129) acts as an opener of $\mathrm{K}^{+}$channels in neuronal cells. Eur J Pharmacol 1997, 336(23):243-249.

27. Luhmann HJ, Mittmann T, Vanluijtelaar G, Heinemann U: Impairment of intracortical GABAergic inhibition in a rat model of absence epilepsy. Epilepsy Res 1995, 22(1):43-51

28. Reid KH, Edmonds HL Jr, Schurr A, Tseng MT, West CA: Pitfalls in the use of brain slices. Prog Neurobiol 1988, 31(1):1-18.

29. Thompson SM, Deisz RA, Prince DA: Relative contributions of passive equilibrium and active transport to the distribution of chloride in mammalian cortical neurons. J Neurophysiol 1988, 60(1):105-24

30. McCormick DA, Prince DA: Two types of muscarinic response to acetylcholine in mammalian cortical neurons. Proc Natl Acad Sci USA 1985, 82(18):6344-6348.

31. Xiao Z, Deng PY, Yang C, Lei S: Modulation of GABAergic transmission by muscarinic receptors in the entorhinal cortex of juvenile rats. $J$ Neurophysio/ 2009, 102(2):659-669.

32. Yoshida M, Alonso A: Cell-type specific modulation of intrinsic firing properties and subthreshold membrane oscillations by the $M(K v 7)$ current in neurons of the entorhinal cortex. J Neurophysiol 2007, 98 (5):2779-2794
33. Shen W, Hamilton SE, Nathanson NM, Surmeier DJ: Cholinergic suppression of KCNQ channel currents enhances excitability of striatal medium spiny neurons. J Neurosci 2005, 25(32):7449-7458.

34. Hamam BN, Sinai M, Poirier G, Chapman CA: Cholinergic suppression of excitatory synaptic responses in layer II of the medial entorhinal cortex. Hippocampus 2007, 17(2):103-113.

35. Sheridan RD, Sutor B: Presynaptic $M_{1}$ muscarinic cholinoceptors mediate inhibition of excitatory synaptic transmission in the hippocampus in vitro. Neurosci Lett 1990, 108(3):273-278.

36. De Fernandez Sevilla D, Rodrigo-Angulo M, Nunez A, Buno W: Cholinergic modulation of synaptic transmission and postsynaptic excitability in the rat gracilis dorsal column nucleus. J Neurosci 2006, 26(15):4015-4025.

37. Gulledge AT, Bucci DJ, Zhang SS, Matsui M, Yeh HH: $M_{1}$ receptors mediate cholinergic modulation of excitability in neocortical pyramidal neurons. $J$ Neurosci 2009, 29(31):9888-9902.

38. Hamilton SE, Loose MD, Qi M, Levey Al, Hille B, McKnight GS, Idzerda RL, Nathanson NM: Disruption of the $\mathrm{m} 1$ receptor gene ablates muscarinic receptor-dependent $\mathrm{M}$ current regulation and seizure activity in mice. Proc Natl Acad Sci U S A 1997, 94(24):13311-13316.

39. Deisz $R A$ : The $G A B A_{B}$ receptor antagonist CGP $55845 A$ reduces presynaptic $G A B A_{B}$ actions in neocortical neurons of the rat in vitro. Neuroscience 1999, 93(4):1241-1249.

40. Deisz RA, Prince DA: Frequency-dependent depression of inhibition in guinea-pig neocortex in vitro by $\mathrm{GABA}_{B}$ receptor feed-back on GABA release. J Physiol (Lond) 1989, 412:513-541.

41. Yamasaki M, Matsui $M$, Watanabe M: Preferential localization of muscarinic $M_{1}$ receptor on dendritic shaft and spine of cortical pyramidal cells and its anatomical evidence for volume transmission. J Neurosci 2010, 30 (12):4408-4418.

42. Richter M, Schilling T, Muller W: Muscarinic control of intracortical connections to layer II in rat entorhinal cortex slice. Neurosci Lett 1999, 273(3):200-202.

43. Moriya H, Takagi Y, Nakanishi T, Hayashi M, Tani T, Hirotsu I: Affinity profiles of various muscarinic antagonists for cloned human muscarinic acetylcholine receptor (mAChR) subtypes and $\mathrm{mAChRs}$ in rat heart and submandibular gland. Life Sci 1999, 64(25):2351-2358.

44. Caulfield MP: Muscarinic receptors - Characterization, coupling and function. Pharmacol Ther 1993, 58(3):319-379.

45. Lanzafame AA, Christopoulos A, Mitchelson F: Cellular signaling mechanisms for muscarinic acetylcholine receptors. Recept Channels 2003, 9(4):241-260.

46. Dasari S, Gulledge AT: M1 and M4 receptors modulate hippocampa pyramidal neurons. J Neurophysiol 2011, 105(2):779-792.

47. Davies $\mathrm{CH}$, Starkey SJ, Pozza MF, Collingridge GL: GABA autoreceptors regulate the induction of LTP. Nature 1991, 349(6310):609-611.

48. Hasselmo ME, McGaughy J: High acetylcholine levels set circuit dynamics for attention and encoding and low acetylcholine levels set dynamics for consolidation. Prog Brain Res 2004, 145:207-231.

49. Buckley NJ, Bonner TI, Buckley CM, Brann MR: Antagonist binding properties of five cloned muscarinic receptors expressed in CHO-K1 cells. Mol Pharmacol 1989, 35(4):469-476.

50. Alkondon M, Pereira EFR, Almeida LEF, Randall WR, Albuquerque EX: Nicotine at concentrations found in cigarette smokers activates and desensitizes nicotinic acetylcholine receptors in CA1 interneurons of rat hippocampus. Neuropharmacology 2000, 39(13):2726-2739.

51. Dutar P, Nicoll RA: Classification of muscarinic responses in hippocampus in terms of receptor subtypes and second-messenger systems: electrophysiological studies in vitro. J Neurosci 1988, 8(11):4214-4224.

52. Teichgraber LA, Lehmann TN, Meencke HJ, Weiss T, Nitsch R, Deisz RA: Impaired function of $G A B A_{B}$ receptors in tissues from pharmacoresistant epilepsy patients. Epilepsia 2009, 50(7):1697-1716.

53. Connors BW, Gutnick MJ: Intrinsic firing patterns of diverse neocortical neurons. Trends Neurosci 1990, 13(3):99-104

doi:10.1186/1471-2202-13-42

Cite this article as: Gigout et al: Distinct muscarinic acetylcholine receptor subtypes mediate pre- and postsynaptic effects in rat neocortex. BMC Neuroscience 2012, 13:42. 